\title{
Empyema thoracis: a problem with late referral?
}

\author{
C W Cham, S M Haq, J Rahamim
}

\begin{abstract}
Background-Patients are often referred to thoracic units for management of empyema after the acute phase has been treated with antibiotics but without adequate drainage. This study evaluates the effects of delay in surgical treatment of empyema thoracis on morbidity and mortality.
\end{abstract}

Methods-Thirty nine consecutive patients were studied from January 1991 to June 1992. Two groups (group 1, 16 patients; group 2, 23 patients) were compared depending on the time spent under the care of other specialists before referral to the thoracic unit (group 1, seven days or less; group 2, eight days or more). The reasons for delay in referral were analysed.

Results-Four patients were treated conservatively with chest drainage alone (all in group 1). Thirty five patients required rib resection and drainage of their empyema (group 1, 12 patients; group 2, 23 patients). Nineteen (all in group 2) of the 35 patients who had rib resections went on to have decortication. The commonest cause of empyema was postpneumonic (37 out of 39 patients). Staphylococcus aureus was the commonest organism isolated. Misdiagnosis (five patients), inappropriate antibiotics (six patients), and inappropriate placement of chest drainage tubes (three patients) all contributed to persistence and eventual progression of empyema. The overall mortality was $10 \%$ and mortality increased with age. The median stay in hospital was 9.5 days (range 7-12 days, $n=4$ ) for patients treated with closed tube drainage only; 18 days (range 10-33 days, $n=16$ ) for patients who had undergone rib resections and open drainage; and 28 days (range $22-49$ days, $n=19$ ) for patients who underwent decortication. The likelihood of having a staged procedure (antibiotics, closed tube drainage, open drainage with rib resection, and finally decortication) increased when closed tube drainage was persevered with for more than seven days. The total hospital stay was positively related with the time before referral for surgical treatment. Anaemia, low albumin concentrations, and worsening liver function were found in group 2 compared with group 1.
Conclusions-Early adequate operative drainage in patients with empyema results in low morbidity, shorter stays in hospital, and good long term outcome. These patients should be treated aggressively and early referral for definitive surgical management is recommended.

(Thorax 1993;48:925-927)

Empyema thoracis has been recognised since the time of Hippocrates ${ }^{1}$ but optimal treatment remains controversial. ${ }^{2-6}$ As early as 1875 Gotthard Bülau advocated closed water seal drainage for empyema. ${ }^{7}$ Berger et al, ${ }^{8}$ however, suggested that immediate drainage was not required for all patients with complicated parapneumonic effusions. Fishman et al ${ }^{9}$ advised early decortication only in unusual circumstances-for example, in immunosuppressed patients-and not as a primary treatment. There is thus a tendency to persevere with antibiotics, thoracentesis, and closed intercostal tube drainage and a general reluctance to refer patients with empyema early for operative surgical management.

The purpose of this study was to determine the causes and the effects of delay in surgical treatment of empyema thoracis on morbidity and mortality.

\section{Methods}

Thirty nine consecutive patients were studied between January 1991 and June 1992. There were 17 men and 22 women, age range 8-84 years. Two groups of patients were compared depending on the time spent under the care of other specialists before referral to the thoracic unit (group 1, seven days or less ( $n=16)$; group 2, eight days or more $(n=23))$. Patients were referred to the thoracic unit from various sources. There were 33 referrals from physicians. The others were referred from casualty (2), radiotherapy (1), paediatrics (2), and direct admissions from general practitioners (1). Haemoglobin, serum proteins, liver function tests, morbidity, total hospital stay, and outcome were recorded. The reasons for delay in referral were considered.

\section{STATISTICS}

Data were analysed with the Statgraphics program (STSC Inc) ${ }^{10}$ on an IBM computer. 
Results are expressed as medians (range). The Mann-Whitney procedure was used for two sample comparisons. Regression techniques were used to evaluate associations between variables. ${ }^{11}$

\section{Results}

Nineteen patients presented with typical symptoms of pleuritic chest pains, general malaise, weight loss, and pyrexia. Misdiagnoses had initially occurred in five of the 39 patients; these included subacute bacterial endocarditis, appendicitis, muscular strain, pulmonary embolism, and influenza.

Four patients were treated conservatively with chest drainage alone (all in group 1). Thirty five patients required rib resection and drainage of their empyema (group 1, 12 patients; group 2, 23 patients). Nineteen of the 35 patients who had rib resections (all in group 2) went on to have decortication.

The commonest cause of empyema was secondary to chest infections (37 out of 39). The other causes were trauma after a road traffic accident (1) and an impacted dental plate (1). Staphylococcus aureus was the commonest organism isolated from pleural fluid and blood (14). The other organisms were Streptococcus pneumoniae (8), Staphylococcus epidermidis (2), Haemophilus influenzae (2), Enterobacter (1), Streptococcus milleri (3), $\beta$-haemolytic Streptococcus (4), mixed anaerobes (2), coliforms (1), Klebsiella (1), and Streptococcus faecalis (1). More than one organism was sometimes isolated from the same patient. Fourteen patients had frank pus but no bacteria were isolated in either pleural fluid or blood cultures. All these patients had already commenced antibiotics before presentation at the thoracic unit. The organism isolated was resistant to the initial antibiotic(s) in six patients. Inappropriate placement of chest drains accounted for the persistence of empyema in three patients.

The results of haemoglobin, serum albumin, and liver function tests of patients in group 2 were worse than those in group 1 (table).

The median duration of stay in hospital for patients treated with closed tube drainage

Haematological and biochemical variables

\begin{tabular}{|c|c|c|}
\hline & Group 1 & Group 2 \\
\hline $\begin{array}{l}\text { Admission haemoglobin }(\mathrm{g} / \mathrm{dl}) \\
\text { Lowest haemoglobin }(\mathrm{g} / \mathrm{dl})\end{array}$ & $\begin{array}{l}13 \cdot 8(12 \cdot 2-15 \cdot 6) \\
13 \cdot 2(11 \cdot 5-13 \cdot 9)\end{array}$ & $\begin{array}{r}12 \cdot 9(12 \cdot 1-14 \cdot 6) \\
9 \cdot 2(8 \cdot 3-12 \cdot 5)^{\star}\end{array}$ \\
\hline $\begin{array}{l}\text { Admission albumin }(\mathrm{g} / \mathrm{l}) \\
\text { Lowest albumin }(\mathrm{g} / \mathrm{l}) \\
\text { Normal range } 35-50 \mathrm{~g} / 1\end{array}$ & $\begin{array}{l}38(31-40) \\
30(28-35)\end{array}$ & $\begin{array}{l}32(30-38) \\
24(20-32)^{\star}\end{array}$ \\
\hline $\begin{array}{l}\text { Admission bilirubin }(\mu \mathrm{mol} / 1) \\
\text { Highest bilirubin }(\mu \mathrm{mol} / 1) \\
\text { Normal range }<17 \mu \mathrm{mol} / 1\end{array}$ & $\begin{aligned} 7(6-8) \\
15(12-21)\end{aligned}$ & $\begin{array}{c}8(6-9) \\
28(17-32)^{\star}\end{array}$ \\
\hline $\begin{array}{l}\text { Admission aspartate transaminase (IU/l) } \\
\text { Highest aspartate transaminase (IU/l) } \\
\text { Normal range }<40 \mathrm{IU} / 1\end{array}$ & $\begin{array}{l}38(32-43) \\
51(45-67)\end{array}$ & $\begin{array}{l}39(32-46) \\
76(57-94)^{\star}\end{array}$ \\
\hline $\begin{array}{l}\text { Admission alkaline phosphatase (IU/1) } \\
\text { Highest alkaline phosphatase (IU/l) } \\
\text { Normal range } 40-120 \mathrm{IU} / 1\end{array}$ & $\begin{array}{c}89(42-131) \\
143(116-189)\end{array}$ & $\begin{array}{c}97(55-128) \\
176(134-207)^{\star}\end{array}$ \\
\hline
\end{tabular}

All results given as median (range).

${ }^{\star} \mathrm{p}<0.05$. only was 9.5 days (range $7-12$ days, $n=4$ ); 18 days (range 10-33 days, $n=16$ ) for patients who had undergone rib resection and open drainage; and 28 days (range 22-49 days, $n=19$ ) for those who underwent decortication. The total hospital stay was positively related to the time spent before referral for surgical treatment $(r=0.67, \mathrm{p}<0.05)$. There were four empyema related deaths in this series $(10 \%)$. The mortality increased with age. There were two deaths from five patients who were over 70 years of age (mortality $40 \%$ ) compared with two deaths from 34 patients below the age of 70 (mortality $6 \%$ ). The time before surgical referral was $>10$ days in three of the four patients who died.

\section{Discussion}

Empyema thoracis is defined as the presence of pus in the pleural cavity. Frank purulence must develop before an effusion is termed an empyema. The empyema may initially lie free in the pleural space but soon becomes encapsulated by fibrinous pleural adhesions. The pus becomes more viscous as fluid is absorbed. Fibrin is continually deposited on the pleural surfaces producing a thickened peel that can form as early as seven to 10 days after the onset of the parapneumonic effusion. ${ }^{12}$ Adequate treatment at this stage usually allows full re-expansion of the lung with no functional impairment. The time of transition from acute to chronic empyema is arbitrary. Experimental animal models of empyema loculate within three days of bacterial invasion with fibroblast invasion evident at five days. ${ }^{13}$ The free pleural fluid from the pleural space is easily drained before the deposition of intrapleural fibrin. As the empyema becomes chronic, however, continuing fibrosis promotes restriction of movement of the chest wall and diphragm leading eventually to a shrunken, immobile hemithorax with crowding of the ribs and scoliosis. Some permanent functional impairment follows even if lung re-expansion is achieved. The patient may be seen at any stage during the evolution from acute to chronic empyema but most of the patients in this series were referred at a late stage after initial treatment with repeat thoracentesis or closed chest tube drainage had failed.

Misdiagnosis contributed to the delay in referral for early surgical intervention in five $\cong$ patients. One patient presented with right flank and right sided abdominal pain. She underwent appendicectomy for a normal appendix before the correct diagnosis of a chest infection emerged. She was referred to the thoracic unit for treatment of her empyema thoracis nine days after admission. Another was diagnosed as suffering from muscular strain and discharged home!

Inadequate and inappropriate antibiotics resulted in progression to empyema in six cases. The initial antibiotic treatment was started by different physicians and, not surprisingly, the treatment varied from mono- 
therapy to double or even triple antibiotic regimes. The principal pathogen isolated in our series was Staphylococcus aureus. It has been suggested that there is an increase in enteric and other Gram negative organisms especially Pseudomonas. ${ }^{14}$ Streptococcus milleri was also thought to be increasing as a cause of pleural empyema. ${ }^{15}$ We have found no increase in anaerobic bacteria but would agree with Hughes $e t{ }^{16}$ that rational use of antibiotics should include combinations of agents effective against anaerobic bacteria (for example, metronidazole) coupled with an agent active against aerobic Gram positive cocci and Gram negative bacilli. If the infection is adequately treated, empyema rarely develops.

Complete drainage of empyemas in the acute stage is important in achieving reexpansion of the atelectatic lung and obtaining a satisfactory clinical outcome. Only four patients were cured of their acute empyema with closed tube drainage alone in this series. Intercostal drainage alone often fails as there is no debridement of the pleural cavity, loculi of pus are not broken down, and drainage is not dependent, allowing pus to collect below the site of the drain. As the initial presentation is usually to a physician, however, it may be that there were other patients with empyema who settled with closed chest tube drainage without coming to the notice of the thoracic unit. Inappropriate placement of chest drains accounted for persistence of empyema in three patients. Ulmer et $\mathrm{al}^{17}$ suggested image guided catheter drainage of the infected pleural space and achieved a cure rate of $81 \%$. Whereas we agree that image guidance would result in more accurate placement of chest tubes, we are concerned that the smaller size of catheters ( $8 \mathrm{Fr}$ to $14 \mathrm{Fr}$ ) recommended would only be appropriate for collections of thin pus.

Patients are often referred to the thoracic unit for empyema management after the acute phase has been treated with antibiotics but without adequate drainage. Thirty five patients required rib resection and drainage of their empyema (group 1, 12 patients; group 2, 23 patients). Nineteen of the 35 patients who had rib resections (all in group 2) went on to have decortication.

The likelihood of having a staged procedure (antibiotics, closed tube drainage, open drainage with rib resection, and finally thoracotomy and decortication) increases when closed tube drainage is persevered with for more than seven days. The decision for operative intervention should be determined within a few days after drainage is instituted. The staged approach to treatment leads not infrequently to unnecessary prolongation of the infective process in patients who may be debilitated by malnutrition, diabetes, or other disease processes. Certainly patients who were referred late for surgical management had a significantly greater incidence of anaemia (four requiring blood transfusion), lower serum albumin, worse liver function, and longer total hospital stay compared with those who were referred early. The prolonged use of antibiotics results in opportunistic infections and one of our patients in group 2 required systemic antifungal treatment for candidiasis. Moreover, there was also increased morbidity for patients in group 2 associated with having to undergo a bigger operation.

The clinical and radiological improvements after decortication are dramatic with immediate lung re-expansion and improvement of the clinical course. We believe that early adequate operative treatment in patients with empyema results in low morbidity, shorter hospital stay, and good long term outcome. These patients can best be treated by more aggressive and definitive surgical management and early referral is recommended.

1 Hippocrates. Genuine works of Hippocrates. Translated by Anderer F. London: Sydenham Society, 1847

2 Kerr A, Vasudevan VP, Poerll S, Ligenza C. Percutaneous catheter drainage for acute empyema. Improved cure rate using CAT scan, fluoroscopy, and pigtail drainage catheters. NY State f Med 1991;91:4-7.

3 Ridley PD, Braimbridge MV. Thoracoscopic debridement and pleural irrigation in the management of empyema thoracis. Ann Thorac Surg 1991;51:461-4.

4 Hoff SJ, Neblett WW, Heller RM, Pietsch JB, Holcomb GW Jr, Sheller JR, et al. Postpneumonic empyema in childhood: selecting appropriate therapy. $\mathcal{F}$ Paediatr Surg 1989;24:659-64.

5 Lee KS, Im JG, Kim YH, Hwang SH, Bae Wk, Lee BH. Treatment of thoracic multiloculated empyemas with intracavity urokinase: a prospective study. Radiology 1991;179:771-5.

6 Aye RW, Froese DP, Hill LD. Use of purified streptokinase in empyema and haemothorax. Am $\mathcal{f}$ Surg 1991;161:560-2.

7 Meyer JA. Gotthard Bülau and closed water-seal drainage for empyema, 1875-1891. Ann Thorac Surg 1989; 48:597-9.

8 Berger HA, Morganroth ML. Immediate drainage is not required for all patients with complicated parapneumonic effusions. Chest 1990;97:731-5.

9 Fishman NH, Ellerston DG. Early pleural decortication for thoracic empyema in immunosuppressed patients. f Thorac Cardiovasc Surg 1977;74:537-41.

10 Brown RA, Swanson Beck J. A non-algebraic guide to their appropriate use in biomedical research and pathology practice. 1. Data handling and preliminary analysis. f Clin Pathol 1988;41:1033-8.

11 Brown RA, Swanson Beck J. A non-algebraic guide to their appropriate use in biomedical research and pathology practice. 4. Correlation and regression. 7 Clin Pathol 1989;42:4-12.

12 DeMeester TR, Lafontaine E. The Pleura. In: Sabiston DC Jr, Spencer FC, eds. Surgery of the chest. 5th ed. Philadelphia: Saunders, 1990.

13 Strange C, Tomlinson JR, Wilson C, Harley R, Miller KS, Sahn SA. The histology of experimental pleural injury with tetracycline, empyema and carrageenan. Exp Mol Pathol 1989;51:205-219.

14 Geha AS. Pleural empyema-changing aetiologic, bacteriologic and therapeutic aspects. $\mathcal{F}$ Thorac Cardiovasc Surg 1975;61:626-35

15 Hocken DB, Dussek JE. Streptococcus milleri as a cause of pleural empyema. Thorax 1985;40:626-8.

16 Hughes CE, Van Scoy RE. Antibiotic therapy of pleural empyema. Semin Respir Infect 1991;6:94-102.

17 Ulmer JL, Choplin RH, Reed JC. Image-guided cathether drainage of the infected pleural space. $\mathcal{F}$ Thorac Imaging 1991;6:65-73. 